\title{
LA TRANSMISIÓN A TÍTULO UNIVERSAL DEL DERECHO MERCANTIL ANTE LA LEY FISCAL
}

\author{
Dr. Jorge W. Ibiñete*
}

\begin{abstract}
RESUMEN. Se analizan las consecuencias tributarias de operaciones de reorganización empresarial (fusión, escisión y asunción del activo y pasivo por el único socio), que comportan transmisión a título universal de todo o una cuota parte del patrimonio de sociedades comerciales, concluyendo que: En estas operaciones no existe contraprestación alguna en favor de la sociedad que se desprende todo o parte alicuota de su patrimonio, por lo que no se genera ningún tributo cuyo presupuesto de hecho suponga la onerosidad. Tampoco pueden desconocerse las formas juridicas dispuestas por la ley para estas operaciones, porque las mismas son acordes con el hecho de que el patrimonio pertenece a la sociedad, y no a los socios; y de que legalmente las nuevas participaciones, cuotas o acciones compensan los derechos personales (de crédito) de los socios o accionistas, y no los de la sociedad. En caso de que en el patrimonio existan derechos reales sobre inmuebles, su transmisión tampoco estará alcanzada por el ITP, porque el hecho generador de dicho impuesto sólo comprende una especie de las transmisiones a título universal, que es la sucesión por causa de muerte o ausencia. - La compensación a los socios o accionistas con participaciones, cuotas o acciones, no es una operación onerosa, desde que los mismos no efectúan ninguna prestación, ni la sociedad que las entrega soporta sacrificio patrimonial alguno. Cuando la compensación se realiza parcialmente en dinero, los socios o accionis-
\end{abstract}

* Doctor en Derecho y Ciencias Sociales de la Universidad de la República; ex asesor letrado de la Dirección General Impositiva. Correo electrónico: jorge.ibiete@gmail.com.

* Abreviaturas: CC: Código Civil; CCom: Código de Comercio; CEE: Comunidad Económica Europea; CGP: Código General del Proceso; Dec.: decreto del Poder Ejecutivo; DGI: Dirección General Impositiva; DL: Decreto Ley; IMEBA, Impuesto a la enajenación de bienes agropecuarios; IP: Impuesto al Patrimonio; IRAE: Impuesto a las Rentas de las Actividades Económicas; IRIC: Impuesto a las Rentas de la Industria y Comercio; IRNR: Impuesto a las rentas de los no residentes; IRPF: Impuesto a la Renta de las Personas Físicas; ITP: Impuesto a las Trasmisiones Patrimoniales; IVA: Impuesto al Valor Agregado; LSC: Ley de Sociedades comerciales, n. ${ }^{\circ} 16.060$ de 04/09/1989; SAFI, Impuesto a las sociedades financieras de inversión; TCA: Tribunal de lo Contencioso Administrativo; TO: Texto Ordenado de la DGI. 
tas se desprenden de parte de sus participaciones, cuotas o acciones, lo que importa un rescate de capital, con eventuales consecuencias fiscales en cabeza de los mismos, de acuerdo con la situación de cada uno. En los casos en que el patrimonio transmitido se confunde con el de otra sociedad, como en la fusión y escisión, se genera un cambio de sujeto pasivo tributario, que impide a la sociedad creada o incorporante la deducción de las pérdidas acumuladas por la sociedad fusionada o escindida. En el caso de la asunción del patrimonio por el único socio, las pérdidas de la sociedad pueden deducirse por el sucesor, porque en esta situación se mantiene la integridad de la empresa, continuándose la actividad de la sociedad personalmente por el ex socio. No obstante, en el caso de que el único socio sea una persona física, se producirá un cambio de sujeto pasivo del IP, en virtud de que el régimen de dicho impuesto está vinculado a la forma jurídica del titular del patrimonio.

PALABRAS CLAVE. Título universal. Onerosidad. Fusión. Escisión. Asunción del activo y pasivo.

ABSTRACT. An analysis of the tax-related consequences of corporate reorganization operations (mergers, demergers, and the acquisition of assets and liabilities by a sole partner) that involve the universal transfer of all or part of the equity of commercial companies, concluding that:

- In these operations, there is no remuneration whatsoever in favor of the company that divests itself of all or of an aliquot share of its equity, and as such there is no tax generated of an amount that is determined to be onerous. - Nor can one ignore the legal forms provided by the law for these operations, seeing as they are consistent with the fact that the equity belongs to the company, and not to the partners; and that, legally, the new equity interests, installments, and shares offset the personal (credit) rights of the partners or shareholders, and not those of the company. If the equity entails in rem rights regarding real property, its transfer will not be reached through the Property Transfer Tax, due to the fact that the event generating said tax only includes one kind of universal transfer, which is succession due to death or absence. Compensation to partners or shareholders with equity interests, installments, or shares is not an onerous operation, since it does not effect any benefit, nor does the company that delivers it bear any loss of equity. When the compensation is paid partially in cash, the partners or shareholders divest part of their equity interests, installments, or shares, which amounts to a recovery of capital, with tax consequences that apply to these individuals, according to the situation of each one. - In cases in which the transferred equity is mixed with that of another company, such as a merger or demerger, there is a change in tax liability, which prevents the created or merging company from deducting the losses accumulated by the merged or demerged company. - In the case of the acquisition of equity by a sole partner, the company's losses can be deducted by the successor, due to the fact that, in this situation, the integrity of the 
company is maintained, with the company's activity continued personally by the former partner. However, in the event that the sole partner is a natural person, there will be a change in the taxpayer for the Property Tax, seeing as the regime for said tax is linked to the legal form of the equity holder.

KEY WORDS. Universal title. Onerosity. Merger. Demerger. Acquisition of assets and liabilities.

\section{INTRODUCCIÓN.***}

1.1. Nos proponemos analizar las consecuencias tributarias de operaciones de reorganización empresarial del derecho mercantil (fusiones y escisiones de sociedades comerciales y operaciones asimiladas, así como la asunción del activo y pasivo de la sociedad por el único socio), que tienen en común la sucesión a título universal en la totalidad o una cuota parte del patrimonio societario, sin la previa liquidación de la sociedad o sociedades cuyo patrimonio se transmite y - en los casos de escisión parcial - sin previa disolución (Arts. $115-117,122$ y 156 LSC).

1.2 En el caso del art. 156 LSC la sucesión - que siempre es total - se efectúa de una sociedad que se disuelve, al único socio, persona física o jurídica. Esta hipótesis se distingue, a su vez, de la distribución que se hace a los socios una vez culminada la liquidación de la sociedad (art. 180 LSC), que implica una transferencia de bienes concretos (no cuotas de patrimonio) a título singular ${ }^{1}$.

\section{RÉGIMEN ANTERIOR A LA LEY 16060 DE 04/09/1989.}

2.1 El tema de las fusiones y sus implicancias fiscales, comenzó a plantearse con intensidad con motivo de la crisis financiera de 1965, iniciada con la corrida contra el Banco Transatlántico. Hasta entonces las fusiones no habían sido reguladas, aunque el art. $1^{\circ}$ de la ley n. ${ }^{\circ} 3.545$ de 19/07/1909 se refería a las mismas (estableciendo que debían ser resueltas en asamblea extraordinaria por una mayoría especial de accionistas y acordando el derecho de receso a los disidentes), al igual que el art. 16 de la ley n. ${ }^{\circ} 13.330$ de 30/04/1965, que las mencionaba como una excepción a la prohibición de la instalación de nuevas instituciones financieras.

En ese escueto marco normativo, la ex Oficina de Impuesto a la Renta compartió el dictamen de su Sala de Abogados, redactado por el Dr. Justo Pastor CALVO, en el que-en

*** Este trabajo tiene como antecedente un dictamen del 30/09/1986, emitido en nuestra entonces calidad de asesor letrado de la Dirección General Impositiva, junto con los Cres. Dora Prado y Ceferino Costa, a quienes debo muchas de las ideas y conceptos aquí expresados.

1 Con anterioridad a la LSC, esta distribución se hacía mediante la partición, al igual que en la sociedad civil o la conyugal (arts. 510 Ccom.; 1937 y 2013 CC). A partir de esta modificación, no puede sostenerse que la disolución de la sociedad genere una comunidad entre los socios o accionistas. La resolución DGI n. ${ }^{\circ}$ 304/1991 de 24/07/1991 asumió esta modificación, declarando que la adjudicación de inmuebles, en los casos de disolución y liquidación de sociedades comerciales, se encuentra gravada por el ITP (criterio luego incorporado al art. $5^{\circ}$ del Dec. n. ${ }^{\circ} 252 / 98$ de 16/09/1998, reglamentario de dicho impuesto), al igual que el art. 17 lit. C) T. 4 TO 1996 (según ley 18.083), al incluir a las adjudicaciones de bienes a los socios o accionistas como hecho generador del IRAE. 
un caso de fusión por creación - se sostuvo que la fusión de sociedades implica una sucesión universal inter vivos, no existiendo "enajenación de establecimientos o casas de comercio", ni incremento patrimonial alguno, en una sociedad que nace ya con el activo y pasivo que se le transmitió por sucesión, ni diferencias de valores del activo establecido para la transferencia y los fiscales de dichos rubros ${ }^{2}$.

2.2 Como consecuencia de la mencionada crisis financiera, se dictaron leyes estimulando la fusión entre las empresas bancarias que habían sobrevivido a la misma.

Es así que el art. 33 inc. $4^{\circ}$ de la ley n. ${ }^{\circ} 13.608$ de 08/09/1967, exoneró de toda clase de impuestos a las fusiones, adquisiciones, absorciones o transferencias de instituciones bancarias que se realizaran en el plazo de tres años; y el art. 50 de la ley n. ${ }^{\circ} 14.057$ de $03 /$ 02/1972, prorrogó por tres años la vigencia de dicha exoneración, estableciendo en su inc. $2^{\circ}$ que "Las fusiones, adquisiciones, absorciones o transferencias aprobadas por los poderes públicos, implica transmisión de patrimonios a título universal y a los efectos de su publicidad, además de su inscripción en el registro público y general de comercio, se otorgará declaratoria que se inscribirá en el Registro de Traslaciones de Dominio, si existieran inmuebles".

2.3 Luego de la ley n. ${ }^{\circ} 14.057$ cit., la posición de la Administración fue oscilante hasta el año 1981. El art. 51 del Dec. 996/1975 de 29/12/1975 (reglamentario del IRIC), asimiló las fusiones y absorciones a las enajenaciones de establecimientos. No obstante, la DGI admitió en la consulta . $^{\circ} 1.026$ de 06/09/1978 ${ }^{3}$, que tratándose de una transmisión a título universal no existe precio, por lo que no se verificaba el IVA ni el IRIC, entre otros impuestos. Este criterio se vio reflejado en la nueva reglamentación del IRIC efectuada por el Dec. n. ${ }^{\circ}$ $663 / 1979$ de 22/11/19794 , cuyo art. 18 suprimió la mención de las fusiones y absorciones, así como de las demás operaciones anteriormente asimiladas a la enajenación de establecimientos.

A pesar de ello, en la consulta de la DGI n. ${ }^{\circ} 1.726 / 1981^{5}$ se volvió al criterio de la onerosidad de la fusión, entendiendo que como contrapartida del patrimonio de la sociedad absorbida que se transmite a título universal, la sociedad absorbente entrega acciones propias a los accionistas de aquella. Poco después, coherente con dicho criterio, el Dec. n. ${ }^{\circ}$ 49/1982 de 10/02/1982, invocando la finalidad de promover la fusión de empresas industriales, en cuanto ello signifique un incremento de la eficiencia, las habilitó para ampararse a los beneficios del DL n. ${ }^{\circ} 14.178$ de 28/03/1974 (Promoción Industrial), "incluyendo los mismos la exoneración de todo tributo que grave directa o indirectamente los actos de constitución y las transferencias de bienes consecuencia de la fusión”. Dicho régimen fue luego extendido por el Dec. n. ${ }^{\circ}$ 494/1991 de 10/09/1991, a las escisiones de sociedades que cumplan con las condiciones antes referidas.

2 CALVO, Justo Pastor. "La fusión de los bancos y sus consecuencias fiscales" en Anales Administrativos, T. I, n. ${ }^{\circ} 10$ (1965), pp. 414-418.

3 Boletín de la DGI, noviembre de 1978, n. 66.

4 Esta norma se mantiene, con variantes de redacción que no modifican su sentido, en el art. 18 del Dec. n. ${ }^{\circ}$ 150/2007 de 26/04/2007, reglamentario del IRAE, actualmente vigente.

5 Boletín de la DGI, diciembre de 1981, n. ${ }^{\circ} 103$. 


\section{LA TRANSMISIÓN A TÍTULO UNIVERSAL}

3.1 El Código Civil regula un único modo de adquirir a título universal, que es la sucesión por causa de muerte o la presunción de muerte causada por la ausencia ${ }^{6}$.

El modo universal de adquirir por acto entre vivos, ha sido reconocido por disposiciones legales expresas ${ }^{7}$, como las de los derechos mercantil y bancario antes citadas ${ }^{8}$, así como por el derecho público, sobre la base de leyes especiales para determinados casos concretos, situaciones a las que se restringe su ámbito de aplicación dado el carácter taxativo que posee la enumeración de los modos de adquirir (art. $705 \mathrm{CC})^{9}$. No obstante, con anterioridad a la vigencia de la ley 14.057 cit., juristas que se expidieron sobre el caso de una fusión de bancos, tanto del punto de vista fiscal como de la regularidad de los títulos de los inmuebles, sostuvieron que comportaba una transmisión a título universal ${ }^{10}$.

3.2 Los arts. 115 y 116 LSC hablan de la transmisión del patrimonio a "título universal", como antes lo había hecho el art. 50 de la ley 14.057 cit. para las instituciones bancarias. Esta expresión puede hacer pensar que la fusión y la escisión son títulos de adquirir el dominio, en el sentido de los arts. 705 inc. $2^{\circ}$ y 769 nral. $3^{\circ} \mathrm{CC}$, lo que debe descartarse de plano porque - al igual que en la sucesión mortis causa - el patrimonio se transmite directamente, como consecuencia de los actos jurídicos mencionados por la LSC, sin la previa existencia de un derecho ad rem $^{11}$ ni de mecanismos intermedios ${ }^{12}$. El art. 122 LSC también se refiere al título, siendo evidente que este "título" no antecede a la adquisición del dominio, sino que se vincula con la publicidad y la oponibilidad a terceros de una transmisión patrimonial ya operada (art. 54 de la ley 16.871 de 28/09/1997) ${ }^{13}$.

Por consiguiente, cuando dicha sucesión tiene por causa el acuerdo de voluntades, no se trata de un contrato de tipo romano, creador de obligaciones, sino del contrato traslativo de los derechos francés e italiano ${ }^{14}$. El acuerdo de voluntades es la causa que opera la sucesión a título universal, al igual que ocurre con la muerte del causante, aunque en este

6 Arts. 705, 776 y 1037 CC.

7 El art. 156 LSC no dice que la transmisión sea a título universal, pero sin dudas es lo que acontece, pues la titularidad del patrimonio social se transmite sin otro requisito que la declaratoria del único socio ante escribano público, que se inscribirá en los Registros correspondientes.

8 Incluyendo en estos últimos, además del art. 50 de la ley n. ${ }^{\circ} 14.057$ cit., los contratos creados por la ley de Bancos, n. ${ }^{\circ} 17.613$ de 27/12/2002.

9 VAZ FERREIRA Eduardo. Tratado de las Sucesiones, T. I, Montevideo, 1967, p. 97; PÉREZ FONTANA, Sagunto, Fusión de Sociedades, Montevideo, 1970, pp. 88-90; JUAMBELTZ, Arturo. "Fusión de Sociedades", en La Justicia Uruguaya, T. 55 (1967), p. 59. En el mismo sentido, el dictamen de la Asociación de Escribanos del Uruguay, aprobado el 06/04/1992, entendió que la fusión de asociaciones civiles no es título universal de adquirir, por lo que los bienes deben ser transferidos mediante acuerdo de voluntades otorgado por las fusionadas y la nueva, seguido por el modo tradición (en Revista de la Asociación de Escribanos del Uruguay., T. 78, 1992, pp. 111-114).

10 CALVO, Justo Pastor. Ob. cit., p. 145 y 147; LAVIÑA, BRUSCHERA, QUEIROLO VARELA y CANON NIETO, en "Fusión de sociedades", cit., pp. 61 y ss.; BARDALLO, Julio. "La fusión de bancos importa transmisión universal entre vivos", dictamen para el SMU, de fecha 26/08/1971, en Revista Asociación de Escribanos cit., T. 58, 1972, pp.133-151.

11 VAZ FERREIRA, Eduardo, Ob. cit., p. 73.

12 VAZ FERREIRA, Eduardo. Ob. cit., p. 85; JUAMBELTZ, Arturo. Ob. cit., p. 57.

13 Cf. DE CORES, Carlos. "Negocios sobre universalidad. Su actualidad a la luz de la reciente Ley de Bancos", en Anuario de Derecho Civil Uruguayo, T. XXXIII, FCU, Montevideo, 2003, p. 523.

${ }_{14}$ GAMARRA, Jorge. Ob. cit., T. Octavo, Montevideo, 1967, pp. 43 y ss. 
caso no se trata de un acto sino de un hecho jurídico ${ }^{15}$. Como señala DE CORES, "Hay un solo hecho o acto que sintéticamente, produce la trasmisión de los activos y pasivos y situaciones complejas, sin necesidad de cumplir actos de tradición, de notificar a los deudores de los créditos, de practicar endosos o registraciones contables, o de requerir la aquiescencia de los acreedores o contrapartes contractuales" ${ }^{\prime 16}$.

3.3.1 En cuanto a la expresión "universal", se refiere al objeto de la adquisición consistente en la totalidad o cuota parte de una universalidad jurídica, que es el patrimonio de la sociedad o sociedades que se disuelven o se escinden parcialmente - y también a la forma en que opera este modo de adquirir, que consiste en “...el cambio de un sujeto por otro en una relación que permanece inalterada..." ${ }^{17}$. La sucesión universal no supone la transferencia de los bienes y deudas, sino la sustitución del titular de las relaciones jurídicas activas y pasivas ${ }^{18}$.

Estos elementos permiten distinguir a los institutos en estudio, no sólo de los negocios a título singular - que también pueden tener por objeto una universalidad jurídica ${ }^{19}$ - sino de aquellos en los que solo se transmite parte del activo (art. 117 inc. $2^{\circ}$ LSC $^{20}$ ) o los mencionados en la ley n. ${ }^{\circ} 17.613$ cit., por los cuales se transmiten determinados activos y pasivos de entidades de intermediación financiera en liquidación, considerados como una universalidad $^{21}$.

3.3.2 A diferencia de la transmisión entre vivos a título singular, que sólo atañe al lado activo de la obligación ${ }^{22}$, en la universal las deudas se transmiten con prescindencia de la voluntad de los acreedores ${ }^{23}$, dentro de los límites de los arts. 127 y 138 LSC. En consecuencia, la responsabilidad del adquirente a título universal es siempre por deuda propia $^{24}$, desde que el mismo sucede (sustituye) al deudor en la obligación, lo que excluye los mecanismos de protección a los acreedores basados en la responsabilidad solidaria, como es el caso del art. $22 \mathrm{CT}$, que solo aplican a los sucesores a título singular ${ }^{25}$.

15 Señala GAMARRA, que el modo sucesión, a diferencia de la tradición, “...no es negocio de cumplimiento; en él la muerte es la causa, el título de adquisición, a diferencia de lo que sucede en los contratos" (GAMARRA, Jorge. Ob. cit., T. Octavo cit., p. 35).

16 DE CORES, Carlos. Ob. cit., p. 523; el destacado en cursiva pertenece al original.

17 GAMARRA, Jorge. Ob. cit., T. XV, Montevideo, 1973, pp. 21-22.

18 GAMARRA, Jorge. Ob. cit., T. Cuarto cit., nota 5 en p. 254.

19 Como es el caso de la cesión de derechos hereditarios (arts. 1767 y ss. CC).

20 Aunque las partes pueden convenir que esta operación quede sometida al régimen de la Sección XII del Cap. I LSC.

21 Cf. DE CORES, Carlos. Ob. cit., pp. 521 y ss.

22 La transmisión entre vivos de la deuda, da lugar a un fenómeno opuesto ? la novación ? que extingue la obligación con el consentimiento del acreedor y la sustituye por una nueva (GAMARRA, Jorge. Ob. cit., T. Cuarto cit. pp.184-186).

23 Sin perjuicio de que los acreedores pueden oponerse a la fusión o escisión si no son desinteresados o debidamente garantizados (128 y 139 LSC); y el acreedor embargante de participaciones sociales en sociedades personales, puede oponerse a la fusión o pedir la liquidación de la cuota del socio deudor (art. 78 inc. $3^{\circ}$ y $4^{\circ}$ LSC).

24 En la escisión parcial sí existe responsabilidad solidaria entre las sociedades que se creen y la escindida (art. 138 LSC), aunque la adquirente del patrimonio responde por deuda propia.

25 ACOSTA CASCO, Natalia, AGOSTINO GIRALDEZ, Sol y AMORETTI TABOADA, Carla. "Responsabilidad Tributaria por sucesión mortis causa”, en Revista Tributaria cit., T. XXXVIII (2011), n. ${ }^{\circ} 221$, p. 209 . 
En el caso de la asunción del patrimonio por el único socio, la ley no establece ningún llamado de acreedores ni limitación alguna de responsabilidad. Esta hipótesis de sucesión, supone que la actividad de la sociedad continúa en las mismas condiciones, sustituyendo el ex socio a la sociedad disuelta en las situaciones jurídicas de que esta era titular.

3.3.3 En el CT no existen normas similares a los arts. 18 y 103, para los casos de sucesión a título universal inter vivos. No obstante, dicha omisión no significa que dichas transmisiones hayan quedado excluida del derecho tributario porque, tratándose de una cuestión no prevista relativa a la obligación tributaria, deben aplicarse las normas del derecho privado (art. 14 inc. $\left.2^{\circ} \mathrm{CT}\right)^{26}$.

3.4 Otro aspecto a considerar, es si la sucesión inter vivos a título universal del derecho mercantil supone la continuidad, tal como ocurre en el derecho sucesorio, que sigue el sistema romano de la continuación de la persona del causante o de la representación por el sucesor de la persona del causante ${ }^{27}$.

Sibien dichas expresiones son ficciones (porque la personalidad jurídica no se transmite y la representación supone un actuar en nombre de otro ${ }^{28}$, sirven para describir metafóricamente la continuidad, que no es consecuencia de esas ficciones, sino de la sucesión universal, que - como vimos anteriormente - opera mediante la sustitución del titular de situaciones jurídicas que permanecen incambiadas. Por consiguiente, si bien no es correcto sostener que la sociedad adquirente continúa la personalidad o representa a la sociedad disuelta o escindida, sí puede afirmarse que es una continuadora de esta, al sustituirla - ocupando su lugar - en situaciones y relaciones jurídicas que permanecen inalteradas ${ }^{29}$. Cabe señalar que no debe confundirse la continuidad de la sucesión universal, con la continuidad de la empresa, que - como veremos en el Cap. VII - son fenómenos que pueden o no coincidir.

4.1 Carácter no oneroso. En general la doctrina considera que el concepto de onerosidad del derecho privado también es aplicable en el derecho tributario-aunque con matices, en virtud de lo dispuesto por el art. $6^{\circ}$ inc. $1^{\circ} \mathrm{CT}$ - aceptando que la existencia de contraprestación es un elemento decisivo para esa determinación ${ }^{30}$. Al respecto BLANCO entiende que la contraprestación, aunque no sea equivalente, configura la onerosidad siempre que tenga relación directa con la entrega del bien o la prestación del servicio y se realice en favor del proveedor (la donación modal deberá considerarse realizada a título oneroso siempre que el modo sea en beneficio del donante); debiendo además tener una función retributiva de la ventaja o provecho (en el mutuo la contraprestación son los intereses y no la mera restitución de lo prestado), la que debe derivar de un sacrificio

26 Cf. VALDÉS COSTA, Ramón. Instituciones de Derecho Tributario, Bs. As., Depalma, 1992, p. 58; FERNÁNDEZ FERNÁNDEZ, Gabriel H. "Aplicación del derecho privado en materia tributaria", Revista Tributaria cit., T. XLIV (2017), n. ${ }^{\circ} 258$, pp. 451 y ss.

27 VAZ FERREIRA, Ob. cit., p. 81.

28 VAZ FERREIRA, Ibídem.

29 El art. 35.3 del CGP reconoce este principio para la materia procesal, al establecer que "En caso de extinción de la persona jurídica, el proceso continuará con quienes la sucedan en su patrimonio".

30 SHAW, José Luis. Impuesto al Valor Agregado - hecho generador, ed. Acali, 1978, pp. 39-45; FAGET; Alberto, "El impuesto a la enajenación de producto agropecuarios", en Revista Tributaria cit., T. XI, n. ${ }^{\circ}$ 63, (1984), p. 456; BLANCO, Andrés. El Impuesto al Valor Agregado, FCU - Fac. Der. UDELAR, 2001, Vol. I., p. 89. 
patrimonial de la contraparte en la operación. La contraprestación debe poder medirse en términos monetarios e implicar un real intercambio de prestaciones, aunque la satisfacción efectiva del contravalor pueda diferirse, con base legítima o sin ella ${ }^{31}$.

4.2 De lo anterior se deriva que estos casos de transmisión a título universal son ajenos a la idea de onerosidad, en virtud de que esta tiene como presupuesto la existencia de una contraprestación, es decir, de una carga, sacrificio o desventaja que sea la contrapartida de la utilidad recibida. Tampoco la sociedad que se disuelve y transmite su patrimonio está en condiciones de recibir beneficio alguno ni de distribuir ese beneficio a los socios, porque ello supondría la previa liquidación, que en estos casos no tiene lugar.

En el caso del art. 156 LSC, la ausencia de contraprestación es incontrastable, porque, sin perjuicio de los antes expresado, la onerosidad tiene por presupuesto la existencia de pluralidad de partes $^{32}$ (nadie puede ser acreedor o deudor de sí mismo).

\section{POSICIÓN DE LA DIRECCIÓN GENERAL IMPOSITIVA DEL TRIBUNAL DE LO CONTENCIOSO ADMINISTRATIVO.}

5.1 A partir del cambio de criterio efectuado por la consulta 1.726/81 cit., la DGI viene sosteniendo que tanto las fusiones y escisiones, como la asunción del activo y pasivo de la sociedad por el único socio, se encuentran gravados por IRIC (actualmente IRAE) e IVA. De acuerdo con las consultas que hemos podido ubicar, la posición de la DGI en cuanto a la fusión, fue sostenida en las consultas 1.726 cit., 3.073 de 10/05/1991 ${ }^{33}$, 4.599 de 20/03/2007 y 5.265 de 03/02/2010, que remite a la $3.437^{35}$; en cuanto a la escisión, en la 3.424 de $21 /$ 06/1994 ${ }^{36}$; y en cuanto a la asunción del patrimonio por el único socio, por la 5.105 de 10/ 12/2008 ${ }^{37}$. La consulta 3.073/91 cit., relativa a la fusión por incorporación de dos sociedades anónimas, fue confirmada por la sentencia del TCA n. ${ }^{\circ} 1.270 / 1993^{38}$.

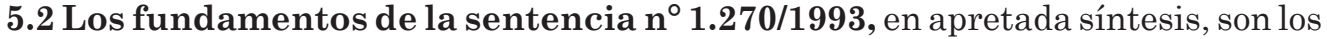
siguientes:

Invocando a PÉREZ FONTANA - quien a su vez sigue a SALANDRA y DE SEMO entiende que el contrato de fusión es decidido por los socios, quienes son representados por los administradores de las sociedades para facilitar el otorgamiento del compromiso y el contrato de fusión.

El contrato de fusión, por su función económica, debe ser considerado dentro de los contratos onerosos, porque cada una de las partes sufre un sacrificio patrimonial, al que corresponde una ventaja patrimonial (contraprestación de la otra parte). Los socios de

31 BLANCO, Andrés. Ob. cit., pp. 87-95.

32 BLANCO, Andrés, Ob. cit., p. 109 y ss.

33 Boletín de la DGI, mayo de 1991, n. ${ }^{\circ} 216$; también en Revista Tributaria cit., n. ${ }^{\circ}$ 120, pp. $253-254$.

34 Publicada en sitio web de la DGI: http://www.dgi.gub.uy/wdgi/page?2,principal,AmpliacionNormativa,O,es,0,PAG;CONC;1075;6;D;consulta-no-4-599;3;PAG;. Última consulta 23/02/2018.

35 La consulta n. 5.265 puede verse en: http://www.dgi.gub.uy/wdgi/page?2,principal,AmpliacionNormativa,O,es,0,PAG;CONC;1074;6;D;consulta-no-5-265;2;PAG; Última consulta 23/02/2018.

36 Boletín de la DGI, junio de 1994, n. ${ }^{\circ} 253$.

37 Publicada en sitio web de la DGI: http://www.dgi.gub.uy/wdgi/page?2,principal,AmpliacionNormativa,O,es,0,PAG;CONC;1074;6;D;consulta-no-5-105;2;PAG; Última consulta 23/02/2018.

38 Rev. Tributaria cit., n. ${ }^{\circ} 120$, pp. 257 y ss. 
la sociedad absorbida reciben, como contraprestación por la transmisión del patrimonio, participaciones o acciones de la sociedad absorbente, siendo indudable que existe por ambas masas sociales el ánimo de obtener una ventaja, provecho o lucro, configurándose una equivalencia subjetiva, no necesariamente objetiva, de las contraprestaciones.

Los accionistas de la sociedad absorbida tienen un cambio radical en su situación, al canjear las acciones de una sociedad por otra con distinta situación financiera y económica y con otro peso en las mayorías. Estima que la operación de fusión es muy similar a la venta de una sociedad, con la diferencia de que el precio no es en dinero sino en acciones.

El beneficio de arrastre de las pérdidas de la sociedad absorbida, no puede transferirse a la sociedad absorbente, porque la atribución del hecho generador debe realizarse al titular de la empresa y no a esta y, en su mérito, el arrastre de perdidas es derecho exclusivo del sujeto pasivo contribuyente en cuya cabeza se genera y no de quien le sucede, siendo por tanto un beneficio intrasmisible.

\section{CRÍTICA A LA POSICIÓN QUE SOSTIENE LA ONEROSIDAD DE LA FUSIÓN Y LA ESCISIÓN.}

\subsubsection{Las partes en la fusión y en la escisión, son las sociedades y no los} socios o accionistas. La tesis de que la fusión y la escisión se otorgan por los socios o accionistas, intenta salvar la contradicción de que, de otro modo, la presunta contraprestación (entrega a los mismos de participaciones, cuotas o acciones) sería en favor de quienes no son parte en la operación, careciendo de carácter retributivo.

No obstante, como señala HOLZ, el art. 120 LSC “...deja en claro que son las sociedades las que otorgan el contrato de fusión o el acto de escisión, y no los socios o accionistas alcanzados por dichas operaciones. El proyecto de ley preveía originalmente que los representantes de la sociedad debían ser considerados además como representantes legales de los socios, lo cual fue eliminado del texto definitivo" 39 .

BLANCO también sostiene esta posición, argumentando que la transmisión del patrimonio opera por voluntad social, aun contra la voluntad de alguno de los socios y aun cuando los disidentes ejerzan el derecho de receso; y porque los mecanismos de protección de los acreedores previstos en la ley 16.060, tanto para la fusión como para la escisión, comprenden a los acreedores de la sociedad y no a los de los $\operatorname{socios}^{40}$.

6.1.2 El patrimonio empresario pertenece a la sociedad y no a los socios. Por otra parte, si bien es cierto que la fusión y la escisión deben ser decididas por los socios o

39 HOLZ, Eva, "Sección XII - De la Fusión y de la Escisión", en Análisis exegético de la ley 16.060 Sociedades Comerciales. En GAGGERO, Eduardo, PÉREZ IDIARTEGARAY, Saúl y RIPPE, Siegbert (Directores), T. I, FCU, Montevideo, 1992, p. 115. El art. 122 del Proyecto, que se corresponde con el art. 120 de la ley aprobada, establecía que los administradores o representantes suscribirán el contrato de fusión o el acto de escisión "...ejerciendo la representación de la sociedad y de sus respectivos socios o accionistas". Disponible en: https://parlamento.gub.uy/documentosyleyes/documentos/versionestaquigraficas/senadores/42/20498/0/PDF?width=800\&height=600\&hl=en_US1\&iframe=true\&rel= nofollow. Última consulta 23/02/2018.

40 BLANCO, Andrés. Ob. cit., pp. 139-140. 
accionistas, ello no significa que los mismos posean legitimación para disponer de un patrimonio cuya titularidad es de la sociedad, aun después de su disolución ${ }^{41}$. Debe distinguirse, entonces, la decisión de los socios de realizar la fusión o escisión, de la fusión o escisión misma ${ }^{42}$, que son actos jurídicos traslativos, que si bien alcanzan con sus efectos a los socios o accionistas, se otorgan por la sociedad. Siendo los institutos que nos ocupan de carácter dispositivo, y no meramente obligacional, la legitimación para disponer es un requisito de eficacia, tal como ocurre en la tradición ${ }^{43}$.

\subsubsection{La idea de la previa adjudicación o afectación de los bienes a los socios} o accionistas, para justificar que la transmisión del patrimonio la hacen estos y no la sociedad, fue insinuada por BORDOLLI ${ }^{44}$, siendo evidente que implica una inadmisible creación de una ficción por vía interpretativa ${ }^{45}$. Por otra parte, dichos institutos refieren a la transmisión a título singular de bienes concretos (y no de un patrimonio o parte alícuota del mismo), además que la adjudicación debe estar precedida de la liquidación de la sociedad $^{46}$; y la afectación al uso privado supone que el socio o accionista retira elementos del activo (bienes concretos, y no cuotas del patrimonio) para consumirlos o usarlos en su vida privada, y no para continuar la actividad empresarial ${ }^{47}$. A todo lo anterior se suma, que el socio o accionista luego no podría transmitir esos bienes sino a título singular - que es lo que la ley pretendió evitar - sin poder incluir a los pasivos (ver supra nral. 3.3.2).

6.1.4 Tampoco es aceptable prescindir de las formas jurídicas para atribuir el patrimonio de la sociedad y el negocio de fusión directamente a los socios o accionistas, siendo que el art. $6^{\circ}$ inc. $2^{\circ} \mathrm{CT}$ no es una norma antielusiva genérica, sino un mecanismo aplicable exclusivamente al caso de inadecuación entre forma y sustancia ${ }^{48}$. En el caso, la prescindencia de la forma implicaría desconocer la personería jurídica de la sociedad

41 Ver supra nota 1.La situación de los socios o accionistas, en relación con la disposición del patrimonio social, pensamos que es similar a la del cónyuge que da su consentimiento para la enajenación por el otro cónyuge de alguno de los bienes gananciales comprendidos en la regla del art. 1971 CC, lo que no lo convierte en parte en el contrato ni en enajenante.

42 Como señala PÉREZ FONTANA, "Lo que es un acto corporativo, si así quiere llamársele, es la decisión de los socios de realizar la fusión, porque es un acto unilateral que puede o no llevarse a cabo pero que por sí solo no constituye una fusión..." (PÉREZ FONTANA, Sagunto. Sociedades Anónimas comentario de la ley 16.060, Vol. II, FCU, 1992, p. 75).

43 Como dice GAMARRA, “...el negocio dispositivo no produce su efecto típico (su efecto real), si el sujeto no está legitimado para realizarlo. Así la tradición hecha por el no propietario, no produce el efecto real, no transfiere el dominio (artículo 775, inciso $2^{\circ}$ ), aunque puede producir otros efectos (65). La legitimación actúa como requisito de eficacia del negocio dispositivo."; en cursiva en el original (GAMARRA, Jorge. Ob. cit., T. Octavo cit. p. 70).

44 BORDOLLI, José Carlos. Intervención en Mesa Redonda sobre la "Ley de Sociedades comerciales y su incidencia en materia tributaria”, en Revista Tributaria IUET, n. ${ }^{\circ} 95$ (1990), pp. 115-116 y 120.

45 SHAW, José Luis. Intervención en Mesa Redonda sobre la "Ley de Sociedades comerciales y su incidencia en materia tributaria”, en Revista Tributaria cit., n. ${ }^{\circ}$ 95, p.122; PEIRANO FACIO, Juan Carlos. "Comentario del Dr. Juan Carlos Peirano Facio sobre la sentencia del Tribunal de lo Contencioso Administrativo, n. ${ }^{\circ} 1.270 / 93$ ”, en Revista Tributaria cit., n. ${ }^{\circ} 120$, p. 270.

46 BLANCO, Andrés. Renta Bruta en el IRAE, en BLANCO, Andrés (Coordinador), Estudios sobre Imposición a la Renta, FCU, $2^{a}$ ed., Montevideo, 2015, p. 346.

47 BLANCO, Andrés. Renta Bruta en el IRAE cit., p. 351.

48 FAGET, Alberto. "Interpretación y calificación en materia tributaria. Las formas jurídicas inadecuadas y el fraude a la ley fiscal”, en Revista Tributaria cit., T. XXXI, n. ${ }^{\circ} 181$ (2004), p. 437; cf. FERRARI REY, Mario y GUTIÉRREZ PRIETO, Gianni, Conjuntos económicos - enfoque tributario, AMF, Montevideo, 2011, pp. 82-89. 
fusionada o escindida, solución extrema que solo puede invocarse cuando la personería ha sido utilizada con la única finalidad de evasión fiscal y sin que exista ningún propósito de negocios ajeno a la materia fiscal. Incluso, en el caso de la existencia de una sociedad con un único socio o accionista, en situaciones cuya legitimidad es admitida por la LSC y su reglamentación, no es concebible que esa circunstancia pueda constituir una causal de "inoponibilidad de la personería jurídica" 49 .

\section{Inexistencia de contraprestación (y de onerosidad), en la fusión y escisión.}

7.1 Las compensaciones de los arts. 115 inc. $3^{\circ}$ y 116 inc. $3^{\circ} \mathrm{LSC}$, pertenecen a los socios y accionistas, y no a la sociedad. Quienes entienden que las participaciones, cuotas o acciones que se entregan a los socios o accionistas constituyen la contraprestación por la transmisión del patrimonio, deben admitir-como lo hace METRE - que las compensaciones en dinero constituyen parte del ingreso que recibe el titular de la empresa que se fusiona ${ }^{50}$. Sin embargo, dicha conclusión se contradice con el art. 124 LSC, porque con ese pago se compensa a los socios o accionistas de un porcentaje del valor nominal asignado a sus participaciones, cuotas o acciones, del cual se desprenden definitivamente. Por otra parte, el hecho de que los derechos de terceros sobre las participaciones y acciones, subsistan en las sustitutivas y en las compensaciones en dinero, no deja dudas de que esas compensaciones no pertenecen a la sociedad, sino a los socios o accionistas.

7.2 Es cierto que lo socios o accionistas tienen la expectativa o esperanza de obtener una ventaja, beneficio o provecho con la fusión o escisión, pero, sin perjuicio de que los mismos no son parte en esas operaciones, esas expectativas imaginadas imposibles de medir en términos monetarios y a veces ilusorias ${ }^{51}$ - no tienen que ver con la causa sino con los motivos, que por ser subjetivos y particulares de cada contratante, no forman parte del contenido del acto y solo poseen relevancia cuando la ley se las otorga ${ }^{52}$. Si bien la ventaja o provecho puede ser futura, o aun eventual o potencial, como en la "compraventa de la esperanza" ${ }^{53}$, una cosa es cuando se trata de una simple expectativa de una de las partes, y otra cuando forma parte de una prestación a cargo de la otra parte.

7.3 Si bien puede hablarse de modos de adquirir gratuitos cuando el adquirente no hace sacrificio patrimonial alguno, consideramos erróneo vincular esa circunstancia a un "ánimo de liberalidad", que sólo puede estar presente en los negocios obligacionales, en los que constituye la causa para obligarse a título gratuito (art. $1287 \mathrm{CC}$ ). En el modo de adquirir a título universal, la causa es un hecho jurídico (la muerte) o un acto jurídico (bilateral o unilateral), al que la ley le atribuye esa eficacia.

\footnotetext{
49 FAGET PRATI, Alberto. "El «disgregard of legal entity» en el Derecho Tributario", en Revista Tributaria cit., T. XX, n. ${ }^{\circ} 116$ (1993), pp. 383 y ss.

50 METRE, Javier. "Adquisiciones, fusiones y reorganizaciones empresariales”, en Revista Tributaria cit. T. XXXVII (2010), n. ${ }^{\circ} 215$, p. 272.

51 La propia LSC prevé en su art. 135 la quiebra o liquidación judicial de la sociedad incorporante o de la que se crea, dentro de los sesenta días de inscripta la fusión.

52 GAMARRA, Jorge. Ob. cit., T. XIV cit. pp. 86-87.

53 BLANCO, Andrés. El Impuesto al Valor Agregado, Vol. 1 cit., p. 104.
} 
No puede justificarse, entonces, la presunta onerosidad de la transmisión universal inter vivos por la inexistencia de ánimo de liberalidad, como lo hace BORDOLLI ${ }^{54}$ y la consulta de la DGI n. ${ }^{\circ} 2.494$ de 15/07/1985 ${ }^{55}$. Como señala GAMARRA, el ánimo de liberalidad "...consiste en el deseo o propósito (finalidad) de realizar una atribución patrimonial sin recibir por ella una contraprestación equivalente”, por lo que “...la causa no es más que la consideración del elemento objetivo en el plano de la mente del sujeto que efectúa el acto gratuito" 56 . No se plantea, entonces, un dilema de causalidad, porque lo primero es el elemento objetivo. Si no existe contraprestación, la afirmación de la onerosidad a partir de la presunta inexistencia de ánimo de liberalidad, no sólo es contraria a la lógica, sino que conduce a la ficción - sin base legal - de asignar carácter oneroso a una operación que no procura ninguna ventaja o provecho a quien realiza la prestación.

7.4 La sentencia que comentamos, asimila la fusión a la venta de una sociedad, considerando que la única diferencia es que en la fusión el precio es en especie. No obstante - sin perjuicio de lo que veremos infra nral. 12.2.2 - para adquirir una sociedad se requiere la compra de la totalidad de sus participaciones o acciones, lo que supone, en primer lugar, que los socios o accionistas se desprendan definitivamente ${ }^{57}$ de las mismas; $y$, en segundo lugar, que el adquirente haga un sacrificio económico a cargo de su propio patrimonio para pagar el precio, ninguna de cuyas circunstancias se verifica en el caso.

7.5 La asimilación también ha sido hecha con el aporte de bienes a la sociedad ${ }^{58}$. Sin embargo, el aporte implica una transmisión a título singular de bienes determinados, y no cuotas de patrimonio, además que ese presunto aporte no se hace por cuenta de los socios o accionistas, desde que los mismos no son titulares de ese patrimonio, ni se desprenden de derecho alguno.

\subsection{La entrega de participaciones sociales, cuotas o acciones, no es una} operación onerosa. La compensación en dinero, sí lo es. Si bien el término "compensación" hace pensar en una contraprestación, entendemos que, más allá de las palabras que con mayor o menor acierto haya utilizado el legislador, lo decisivo para calificar esta operación es el contenido que subyace en la misma.

Por consiguiente, analizaremos por separado las dos hipótesis de compensación mencionadas por el art. 124 LSC, si bien cabe consignar que en ninguno de los casos se trata de indemnizar un perjuicio, desde que la fusión y la escisión lógicamente se otorgan con la expectativa de obtener un beneficio, sobre cuya base incluso se ha pretendido fundar la onerosidad de dichas operaciones (supra nral. 7.2).

${ }^{54}$ BORDOLLI, José Carlos. Intervención en Mesa Redonda cit., en Revista Tributaria cit., n. ${ }^{\circ}$ 95, p. 121.

${ }_{55}$ Revista Tributaria IUET, T, XXI, n. ${ }^{\circ} 120$ (1994), pp. 264-266. En dicha consulta se afirma que estará comprendido en la onerosidad todo acto "...que no esté realizado con ánimo de liberalidad por parte de quien con él se grava, o sea que la onerosidad surge por añadidura del descarte de dicho ánimo".

${ }^{56}$ GAMARRA, Jorge. Ob. cit., T. Octavo cit., p. 157; T. Sexto, Montevideo, 1966, p. 17.

${ }^{57}$ Señala GAMARRA que los contratos de cambio tienen por finalidad producir un traspaso definitivo de la propiedad; en los mismos las partes están enfrentadas como dos adversarios, y lo que una obtiene de ganancia, lo logra a expensas de la otra, fenómeno que no se presenta en el contrato de sociedad, cuya finalidad “...no consiste en el intercambio de bienes, sino más bien en la reunión de fuerzas y de bienes hacia un bien común" (GAMARRA, Jorge. Ob. cit., T. Octavo cit., pp. 127-129).

58 PEIRANO FACIO, Juan Carlos. Ob. cit., p. 272. En ese sentido afirma PEREZ FONTANA que "La naturaleza jurídica de la fusión es la misma que la constitución de una sociedad o el ingreso a una sociedad ya existente" (Manual de Sociedades Anónimas, 2a ed., FCU, 1987, n. ${ }^{\circ} 382$. p. 217). 
8.2 Cuando la compensación es en participaciones, cuotas o acciones, no puede decirse que los socios o accionistas se desprendan de sus derechos como tales, sino que el objeto sobre el que recaen los mismos se traslada a la sociedad creada o incorporante, lo que explica que los derechos de terceros subsistan en las nuevas participaciones, cuotas o acciones y en las compensaciones que se hayan convenido (art. 124 inc. $2^{\circ}$ LSC). Tampoco transfieren un patrimonio que no les pertenece, ni realizan ninguna prestación a favor de dichas sociedades (antes bien, ingresan como potenciales acreedores de la sociedad), por lo que no existe un intercambio de prestaciones. En realidad la asignación a los socios o accionistas de las participaciones, cuotas o acciones sustitutivas, se efectúa en el contrato de fusión o en el acto de escisión (art. $124 \mathrm{LSC}$ ), por lo que si existe un desplazamiento patrimonial el mismo es el resultado de la sucesión universal que implican dichas operaciones, mientras que la entrega a la que refiere dicha norma, no hace más que documentar los derechos que los socios o accionistas ya poseían desde la fusión o escisión. Obsérvese, además, que en el caso de fusión por incorporación o de la escisión parcial en favor de una sociedad existente al amparo del art. 117 inc. $1^{\circ} \mathrm{LSC}$, la entrega también debe efectuarse a los socios o accionistas de la sociedad incorporante, a pesar de que estos claramente no realizan prestación alguna en favor de dicha sociedad.

La sociedad que se crea o incorporante, a su vez, no hace sacrificio patrimonial alguno, desde que la entrega de las nuevas participaciones, cuotas o acciones la hace con cargo al patrimonio recibido con la fusión o escisión.

Esa ausencia de prestaciones y de sacrificio de contenido económico, también impide que la operación pueda considerarse como una permuta de participaciones, cuotas o acciones, como hipotéticamente plantea $\mathrm{BLANCO}^{59}$, sin perjuicio de que no existen al mismo tiempo dos participaciones, cuotas o acciones que puedan intercambiarse, sino que el objeto de cada una se desplaza - junto con el patrimonio - de una sociedad a otra, que adquiere por el modo sucesión la condición de deudora de las obligaciones correlativas.

8.3 En cambio, cuando se compensa en dinero hasta el diez por ciento del valor nominal adjudicado a cada socio o accionista (art. 124LSC), sí puede decirse que estos se desprenden definitivamente de los respectivos derechos, en una operación que a nuestro juicio puede calificarse como de rescate de capital social, como veremos más adelante.

9.1 En lo que refiere a la asunción del activo y pasivo de la sociedad por el único socio, es indiscutible que no hay, ni podría haber, contraprestación alguna, porque nadie puede ser acreedor o deudor de sí mismo.

10. Es cierto que los arts. 26 de la ley 16.906 de 07/01/1998 (Promoción y Protección de Inversiones) y 68 del Título 4 TO cit., permiten exonerar de IRAE (antes IRIC), IVA e ITP operaciones que suponen transmisión patrimonial a título universal. Sin embargo, como señala BLANCO, la exoneración de actos o hechos que están excluidos del hecho generador, debe considerarse como una solución superabundante, como lo confirma el hecho de que el art. 26 de la ley 16.906 faculta al Poder Ejecutivo para exonerar del IVA a la "transformación de sociedades", las cuales - en criterio compartido incluso por la propia DGI - nunca configuran el hecho generador del IVA"60.

59 BLANCO, Andrés. "Renta bruta en el IRAE" cit., p. 349.

60 BLANCO, Andrés. El Impuesto al Valor Agregado, Vol. I cit. p. 140. 
11. Nuestra posición, en este punto, concuerda con las XXV Jornadas Latinoamericanas de Derecho Tributario (Cartagena de Indias, 2010), en relación al tema Fusiones, Adquisiciones y Reorganizaciones Empresariales ${ }^{61}$, en las conclusiones 8. y $10^{62}$. No compartimos, en cambio, la conclusión $11 .{ }^{63}$, por considerar que las compensaciones a los socios y accionistas no poseen carácter indemnizatorio.

\section{CONSECUENCIAS FISCALES DE LA TRANSMISIÓN A TÍTULO UNIVERSAL INTER VIVOS.}

12. Las consultas de la DGI citadas supra nral. 5.1, consideran implícitamente ${ }^{64}$ y en alguna ocasión en forma expresa (como en la n. ${ }^{\circ} 4.599$ cit.), que las consecuencias fiscales de la fusión y escisión deben atribuirse a la sociedad, lo que se contradice con la tesis de que dichas operaciones son efectuadas por los socios o accionistas. PEIRANO FACIO, en cambio, salva esa incongruencia entendiendo que dichas consecuencias deben analizarse en cabeza de los socios o accionistas ${ }^{65}$, aunque incurre en la contradicción de atribuir a estos la titularidad del patrimonio social, al tiempo que afirma que los aportes en bienes están gravados $^{66}$, lo que demuestra que la onerosidad de estas operaciones no puede sostenerse sin incurrir en serias contradicciones ${ }^{67}$.

12.1 En la sucesión universal no se crea una nueva relación jurídica, que tenga por objeto la obligación de una de las partes de transferir el activo y pasivo, sino que el sucesor sustituye al titular en todas las relaciones jurídicas activas y pasivas, no existiendo en

${ }^{61}$ RECOMENDACIONES ADOPTADAS POR LAS XXV JORNADAS LATINOAMERICANAS DE DERECHO TRIBUTARIO. TEMA 1 - FUSIONES, ADQUISICIONES Y REORGANIZACIONES EMPRESARIALES, en Revista Tributaria cit., T. XXXVII (2010), n. ${ }^{\circ}$ 215, pp. 360-361.

62 "8. Las normativas de los países deben dejar en claro que, sin perjuicio de lo dispuesto por las normas de derecho privado, con fundamento en la autonomía dogmática del derecho tributario sustancial, las operaciones integrantes de los procesos de fusión o escisión no entrañan enajenaciones de activos o patrimonios, ni materializan plusvalías que, como tales, evidencien la configuración de hechos generadores de los impuestos sobre la renta, sobre el valor agregado y demás tributos cuya hipótesis de incidencia estén asociados a tales supuestos. En el caso de otras formas de reorganización empresarial, la normativa tributaria debe igualmente consagrar la neutralidad fiscal". "10. La neutralidad impositiva derivada de las reorganizaciones empresariales se extiende a los accionistas y socios. Los intercambios de participaciones o acciones derivados de un proceso de reorganización no generan un incremento susceptible de gravarse con el impuesto sobre la renta".

63 "11. Cuando la relación de canje se integre con compensaciones en dinero destinadas a mantener su equilibrio, estas últimas no constituyen la materialización de una plusvalía por parte de los socios o accionistas que las perciben por tener naturaleza compensatoria o resarcitoria y, por tanto, el importe de las mismas sólo debe incidir en el costo computable de las acciones".

${ }_{64}$ Afirman que la fusión o escisión generan IRIC o IRAE e IVA, sin tener en cuenta la calidad que tengan los socios o accionistas.

65 PEIRANO FACIO, Juan Carlos. Ob. cit., p. 273.

${ }^{66}$ La afirmación de que los aportes en bienes están gravados por impuestos, supone que esos bienes pasan a un patrimonio diferente al del socio o accionista, porque la onerosidad supone la existencia de dos partes independientes que intercambian prestaciones.

67 En la Mesa Redonda antes cit. el Cr. ROSSETTO objetó al Dr. BORDOLLI que la sociedad que desaparece no puede ser contribuyente, porque no recibe nada; a lo que este respondió que tampoco el accionista sería contribuyente si no es el enajenante (Revista Tributaria cit., T. XVII, n. ${ }^{\circ} 95$ cit., pp. 121-122). La solución a esa contradicción sería considerar que el socio o accionista es el otorgante de la fusión o escisión, hipótesis que hemos descartado por ilegal (supra nral. 6.1.1). 
realidad circulación o entrega de bienes ${ }^{68}$. Si bien el hecho generador del IVA es de los denominados "sustanciales" o "económicos", la definición legal no abarcó a todas las situaciones en las que la disponibilidad económica de un bien pasa de un sujeto a otro, sino que solo se refiere a operaciones a título singular cuyo objeto es la entrega de un bien concreto, como lo demuestran todos los ejemplos que enumera el art. $2^{\circ}$ lit. A) del Título 10 TO cit. para aclarar la definición legal. Por otra parte, el impuesto busca gravar el consumo, lo que constituye una hipótesis ajena a la transmisión a título universal de un patrimonio, o cuota parte del mismo. Si bien en nuestro Derecho no existe una disposición que excluya delIVA a las universalidades, como señala $\mathrm{BLANCO}^{69}$, a nuestro juicio dicha exclusión se produce como consecuencia del modo de adquirir a título universal, que no implica la entrega ni el consumo de bienes.

De todos modos es claro que sin una ficción legal, operaciones que carecen de contraprestación no pueden considerarse realizadas a título oneroso a los efectos del IVA ${ }^{70}$; y que al verificarse una transmisión directa del patrimonio, se excluye la existencia de fenómenos intermedios, como la adjudicación o la afectación al uso privado de los socios o accionistas, sin perjuicio de lo expresado en el nral. 6.1.3 en cuanto a las características de estas figuras, que las hacen incompatibles con la transmisión a título universal.

12.2.1 También es claro que operaciones que carecen de contraprestación no pueden tener un "producido" o "resultado" a los efectos del IRAE, porque ambos términos aluden a la retribución que se obtiene por la realización de las operaciones mencionadas en la ley ${ }^{71}$.

12.2.2 En cuanto a la asimilación con la enajenación de establecimientos comerciales (art. 17 lit F Título 4 TO), debe tenerse en cuenta que en esta solo se transmiten los elementos activos y que este hecho generador supone la existencia de un precio, además que esta asimilación fue dejada de lado por el Poder Ejecutivo en 1979 (supra nral. 2.3). Por otra parte, como señala BLANCO, también la enajenación de establecimientos comerciales se asemeja a la venta de la totalidad de las acciones o cuotas sociales, sin que la Administración haya sostenido que esta hipótesis de renta bruta se extienda a estas últimas modalidades de transferencia de empresas ${ }^{72}$.

12.2.3 Si en el patrimonio se incluyen derechos reales inmobiliarios, su transmisión no estará alcanzada por el ITP, no por falta de contraprestación, sino porque este impuesto sólo grava una especie de las transmisiones a título universal, que es la sucesión por causa de muerte o ausencia (lit. E] del art. $1^{\circ}$ del Título 19 del TO cit.), cuya previsión expresa corrobora que las transmisiones a título universal no pueden subsumirse en el concepto de

68 En ese sentido, la Sexta Directiva de la CEE, en cuanto al IVA, faculta a los Estados miembros para considerar que la transmisión de una universalidad no supone una entrega de bienes y que el beneficiario continúa la personalidad del cedente. Según DEROUIN el fundamento de esta exclusión es que la transmisión de universalidades patrimoniales no comporta ni la producción (en sentido amplio) ni el consumo de bienes, razón por la cual no generan valor agregado en sentido económico y, por tanto, carece de sentido su gravamen (citado por BLANCO, Andrés. El Impuesto al Valor Agregado, Vol. I cit., p. 71).

69 BLANCO, Andrés. Ibidem.

70 BLANCO, Andrés. Ob. cit., Vol. I, p. 124.

71 BLANCO, Andrés. "Imposición a la Renta" en BLANCO, Andrés (Coordinador), Estudios sobre Imposición a la Renta cit., pp. 22-23.

72 BLANCO, Andrés. "Renta Bruta en el IRAE" cit. p. 349. 
enajenación previsto en el lit. A) de dicho artículo. Como señala VILLANUSTRE, la ley se apartó del concepto amplio de enajenación que contenía el proyecto - comprensiva de todo tránsito de un bien de un patrimonio a otro - sin dar una definición ni apartarse del derecho civil, legislación y doctrina, para los cuales enajenación equivale a negocio dispositivo traslativo, que significa la confluencia de título y modo ${ }^{73}$, lo que excluye a la sucesión universal. El art. $5^{\circ}$ inc. $1^{\circ}$ del Dec. 252/1998 cit., al incluir en el concepto de enajenación a las fusiones y escisiones, se contradice con su propio concepto de enajenación, equivalente al negocio obligacional, inexistente en estos casos.

12.3 En cuanto a la asunción del activo y pasivo por el único socio, la Consulta de la DGI n. ${ }^{\circ} 5.105$ cit. entendió que "La transferencia de bienes de una persona jurídica a una empresa unipersonal es una circulación, y como tal se halla gravada por el IVA. Cabe agregar también, que se encuentra gravado por el IRAE el resultado proveniente de esta transferencia de bienes".

Indudablemente la consulta no tomó en cuenta que en el caso se trata de una transmisión a título universal, ni que la contraprestación es imposible tratándose de un acto unilateral del único socio. Por otra parte, la afirmación de la circulación del patrimonio de la sociedad hacia el socio, no se concilia con la tesis de que son los socios quienes disponen del patrimonio de la sociedad.

En cuanto al IRAE, la falta de contraprestación hace que la operación carezca de un "producido" o "resultado", no tratándose tampoco de una situación asimilable a la adjudicación o dación en pago que menciona el art. 17 lit. C) Título 4 cit., que son actos bilaterales que suponen la entrega de bienes concretos (no de una universalidad) y-en el primer caso - implica la previa liquidación de la sociedad.

12.4 Para la sociedad que recibe todo o parte del patrimonio de la sociedad fusionada o escindida, se trata de un aumento del capital integrado que no genera rentas gravadas, de acuerdo con lo previsto en el arts. 18 lit. B) T. 4 TO cit. y 15 del Dec. 150/2007.

Como afirma PEIRANO FACIO, para la sociedad incorporante no existen otros efectos tributarios que los resultantes de mantener como valor fiscal inicial de los bienes que se incorporan el valor que los mismos tenían en la sociedad absorbida a la fecha del contrato defusión (art. 66 del Dec 840/88) 74 $^{74}$ disposición que también exigía mantener los regímenes de valuación y de amortización. El art. 66 del Dec. 840/88 cit. fue reproducido por el art. 72 del Dec. 150/2007 cit., con las variantes de que incluyó expresamente a las fusiones y escisiones; y que en la nueva redacción dada al inciso primero por el Dec. 222/2011 de 23/ 06/2011, se agregó que la empresa sucesora también debe mantener el cómputo de los plazos para aplicar las normas sobre malos créditos. En cuanto a la disposición sobre la avaluación del valor llave, que el inc. $2^{\circ}$ del art. 72 cit. mantuvo sin variantes con respecto al antecedente citado, es inaplicable a los casos de transmisión a título universal, en virtud de que en los mismos no existe precio ni inversión real alguna por dicho concepto.

13.1.1 Con respecto a la situación de los socios o accionistas, en el nral. 8.2 adelantamos opinión en el sentido de que, cuando la compensación se efectúa mediante la entrega de

\footnotetext{
${ }_{73}$ VILLANUSTRE NANO, Hugo. "Impuesto a las Trasmisiones Patrimoniales", en Revista Tributaria cit., T. XX, n. ${ }^{\circ} 113$ (1993), pp. 140-141.

${ }^{74}$ PEIRANO FACIO, Juan Carlos. Ob. cit., p. 273.
} 
participaciones, cuotas o acciones, no implica que los mismos se desprendan de sus derechos como tales, ni que efectúen prestación alguna, además que tampoco la sociedad hace un sacrificio económico, porque entrega las nuevas participaciones, cuotas o acciones con cargo al capital recibido de la sociedad fusionada o escindida.

13.1.2 En cuanto al IVA, entendemos que esta operación no configura el elemento material, en virtud de la inexistencia del elemento onerosidad, antes mencionada ${ }^{75}$.

13.1.3 En cuanto al IRPF, no se trata de una operación que genere un incremento patrimonial o un rendimiento de capital. En el primer caso, entendemos que no se verifica ninguna de las hipótesis previstas en el art. 17 Título 7 cit., en virtud de que el socio o accionista no enajena ningún bien corporal o incorporal, que es la hipótesis sobre la que reposa este hecho generador. En el segundo aspecto, es evidente que tampoco percibe renta alguna por la sola documentación de los derechos de los que ya era titular desde el momento de la fusión o escisión.

13.2.1 En el caso de la compensación parcial en dinero, ocurre un fenómeno distinto, de naturaleza económica, por cuanto el socio o accionista se desprende definitivamente de una cuota parte de sus participaciones, cuotas o acciones. Esta “compensación" - que no tiene carácter indemnizatorio de un perjuicio - a nuestro juicio constituye un rescate de capital.

13.2.2 Cuando el socio o accionista es una persona física, será un incremento patrimonial alcanzado por el IRPF, estando exonerado siempre que se trate del rescate en entidades contribuyentes del IRAE, IMEBA, SAFI, o exoneradas de dichos tributos en virtud de normas constitucionales (art. 27 lit. D del Título 7 TO cit.), rigiendo la misma exoneración para el IRNR, si el socio o accionista es una persona física o entidad no residente (arts. $1^{\circ}$ y 15 lit. D del Título 8 TO cit.). Eventualmente podrá también existir un rendimiento de capital, a los efectos del IRPF e IRNR, en virtud de que “...se considerará dividendo la parte del precio del rescate que exceda al valor nominal de las acciones correspondientes" (arts. 19 del Dec. 148/2007, de 26/04/2007 y 8 Dec. 149/2007 de 26/04/ 2007).

13.2.3 Si el socio o accionista fuera un contribuyente de IRAE comprendido en el lit. A) del art. $3^{\circ}$ del Título 4 cit., el ingreso originado por esta operación constituirá renta bruta de dicho tributo (art. 16 lit. B Título 4 cit.).

13.2.4 La ganancia que eventualmente pudiera obtener la sociedad creada o absorbente con esa operación, no constituye renta bruta (art. 18 lit. B Título 4 TO cit.).

13.2.5 Con respecto al IVA, tratándose de pagos al socio o accionista que se hacen efectivos en dinero, no se configura el aspecto material del $\mathrm{IVA}^{76}$.

\section{EL ARRASTRE DE PASIVOS}

14.1 En este punto compartimos el criterio de la DGI y la sentencia referida, en virtud de que el derecho a deducir de la renta bruta las pérdidas de los ejercicios anteriores (art. 21 Lit. F] del Título 4 del TO cit.), no es un crédito que habilite para exigir una prestación,

75 BLANCO, Andrés. El Impuesto al Valor Agregado, Vol. I cit., pp. 134-136.

76 Cf. BLANCO, Andrés. El Impuesto al Valor Agregado, Vol. I cit., p. 136. 
sino que, al igual que en el régimen general del IVA, sólo es una deducción acordada por la ley para liquidar el impuesto, lo que le impone un límite temporal natural, que es la propia existencia del contribuyente ${ }^{77}$.

14.2 El derecho a deducir las pérdidas de ejercicios anteriores no puede pasar, entonces, a un sujeto pasivo diferente, como ocurre en los casos de fusión y escisión, porque - a pesar de que en dichos casos existe continuidad en el patrimonio transmitido - el mismo se fragmenta y/o se confunde con otros patrimonios, provocando el cese de la empresa fusionada o escindida y un cambio de sujeto pasivo. Aunque la atribución de las rentas debe realizarse al titular de la empresa, y no a esta, como se señala en la sentencia, la empresa es un elemento necesario para la definición de las rentas gravadas, por lo que su identidad se vincula a la del sujeto pasivo tributario, lo que - por remisión - también se proyecta al campo del IVA.

Por consiguiente, consideramos que en esos casos no es aplicable la recomendación n. ${ }^{\circ}$ 9. de las ya mencionadas Jornadas Latinoamericanas de Derecho Tributario, en el sentido que "Las reorganizaciones empresariales deben conllevar el traslado de atributos fiscales, incluyendo el de las pérdidas fiscales"78.

15. La conclusión es diferente en el caso de la asunción del patrimonio por el único socio, en virtud de que en esta modalidad la empresa mantiene su integridad y el socio continúa personalmente la actividad de la sociedad. Este caso entendemos que está excluido del cierre de ejercicio, en virtud de que esa situación está comprendida en la referencia que hace el art. 36 del Dec. 597/1988 de 21/09/1988 (reglamentario de las normas formales y materiales de los tributos recaudados por la DGI) al "modo sucesión", además que no implica clausura - porque la actividad continúa-ni transferencia ${ }^{79}$, porque dicha norma - coincidiendo con el criterio doctrinario referido supra nral. 3.31 - ha diferenciado los casos de transferencia, de los "cambios de titular" de determinadas universalidades jurídicas ${ }^{80}$.

En cambio, cuando la transmisión se produce en favor de una persona física, sí se produce un cierre de ejercicio del IP, porque el régimen de dicho impuesto ha sido definido atendiendo a la forma jurídica del titular del patrimonio.

\section{BIBLIOGRAFÍA CONSULTADA}

ACOSTA CASCO, Natalia, AGOSTINO GIRALDEZ, Sol y AMORETTI TABOADA, Carla. "Responsabilidad Tributaria por sucesión mortis causa", en Revista Tributaria IUET, T. XXXVIII (2011), n. ${ }^{\circ} 221$, pp.193 y ss.

BARDALLO, Julio. "La fusión de bancos importa transmisión universal entre vivos", dictamen para el S.M.U., de fecha 26/08/1971, en Revista Asociación de Escribanos del Uruguay, Montevideo, T. 58 (1972), pp.133-151.

BLANCO, Andrés. - El Impuesto al Valor Agregado. FCU - Fac. Der. UdelaR, Vol. I, 2001; Vol. II, 2004; - "Imposición a la Renta" y "Renta bruta en el IRAE", en BLANCO, Andrés

77 BLANCO, Andrés. El Impuesto al Valor Agregado cit., Vol. II, 2004, pp. 149-152 y 184-185.

78 RECOMENDACIONES ADOPTADAS POR LAS XXV JORNADAS LATINOAMERICANAS DE DERECHO TRIBUTARIO cit., p. 361.

${ }^{79}$ La normativa tributaria prevé dos motivos para el cese anticipado del contribuyente: las cesaciones de negocios y las transferencias (art. 89 T. 4 TO cit.).

80 El art. 18 del Dec. 150/2007 cit. utiliza un concepto amplio de "transferencia", pero asociado a operaciones a título oneroso. 


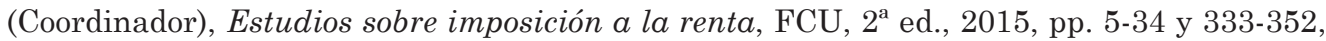
respectivamente.

BORDOLLI, José Carlos. - "Ley de sociedades Comerciales y su incidencia en materia Tributaria" e intervenciones en el Debate que siguió a esa disertación, en Revista Tributaria IUET, T. XVII (1990), n. ${ }^{\circ} 95$, pp. 81 y ss.; - "Consecuencias tributarias nacionales e internacionales de la escisión de empresas", en Revista Tributaria IUET, T. XXI (120), p. 227 y ss.; - "Comentario del Dr. José C. Bordolli sobre la sentencia del Tribunal de lo Contencioso Administrativo n. ${ }^{\circ}$ 1270/93", en Revista Tributaria cit., n. ${ }^{\circ} 120$, pp. 263-264.

CALVO, Justo Pastor. "La fusión de los bancos y sus consecuencias fiscales" en Anales Administrativos, T. I, n. ${ }^{\circ} 10$ (1965), pp. 414-418.

DE CORES, Carlos. "Negocios sobre universalidad. Su actualidad a la luz de la reciente Ley de Bancos", en Anuario de Derecho Civil Uruguayo, T. XXXIII, FCU, Montevideo, 2003.

FAGET; Alberto A. - "El impuesto a la enajenación de productos agropecuarios", en Revista Tributaria IUET, T. XI, n 63 (1984), pp. 449 y ss.; - "Interpretación y calificación en materia tributaria. Las formas jurídicas inadecuadas y el fraude a la ley fiscal", en Revista Tributaria cit., T. XXXI, n¹81 (2004), pp. 431 y ss.; - "El «disgregard of legal entity» en el Derecho Tributario", en Revista Tributaria cit., T. XX, nº 116 (1993), pp. 369 y ss.

FERNÁNDEZ FERNÁNDEZ, Gabriel H. "Aplicación del derecho privado en materia tributaria”, Revista Tributaria IUET, T. XLIV (2017), n. ${ }^{\circ} 258$, pp. 451 y ss.

FERRARI REY, Mario y GUTIÉRREZ PRIETO, Gianni, Conjuntos económicos-enfoque tributario, AMF, Montevideo, 2011.

GAMARRA, Jorge. - Tratado de Derecho Civil Uruguayo, T. Cuarto, $3^{\mathrm{a}}$ ed., Montevideo, 1981 - T. Octavo, Montevideo, 1967; - T. Sexto, Montevideo, 1966 - T. XIII, Montevideo, 1971 - T. XIV, Montevideo, 1972 - T. XV, Montevideo, 1973.

HOLZ, Eva. "Sección XII - De la Fusión y de la Escisión", en GAGGERO, Eduardo, PÉREZ IDIARTEGARAY, Saúl y RIPPE, Siegbert (Directores), Análisis exegético de la ley 16.060 Sociedades Comerciales, T. I, FCU, Montevideo, 1992.

JUAMBELTZ, Arturo, LAVIÑA, Félix, BRUSCHERA y QUEIROLO VARELA, Mateo, Fusión de Sociedades, en La Justicia Uruguaya, Montevideo, T. 55 (1967), pp. 55 y ss. de la sección Doctrina.

METRE, Javier. "Adquisiciones, fusiones y reorganizaciones empresariales”, en Revista Tributaria IUET, T. XXXVII (2010), n. ${ }^{\circ} 215$, pp. 245 y ss.

PEIRANO FACIO, Juan Carlos. "Comentario del Dr. Juan Carlos Peirano Facio sobre la sentencia del Tribunal de lo Contencioso Administrativo n. ${ }^{\circ}$ 1279/93”, en Revista Tributaria IUET, T. XXI (1994), n. ${ }^{\circ} 120$, pp. 267 y ss.

PÉREZ FONTANA, Sagunto. - Fusión de Sociedades. Montevideo, 1970;-Manual de Sociedades Anónimas, $2^{a}$ ed. corregida y actualizada, FCU, 1987; - Sociedades Anónimas - comentarios a la ley 16.060, Vol. II, FCU, 1992.

"RECOMENDACIONES ADOPTADAS POR LAS XXV JORNADAS LATINOAMERICANAS DE DERECHO TRIBUTARIO. TEMA 1 - FUSIONES, ADQUISICIONES Y REORGANIZACIONES EMPRESARIALES”, en Revista Tributaria IUET, T. XXXVII (2010), n. ${ }^{\circ} 215$, pp. 359 y SS.

SHAW, José Luis. - Impuesto al Valor Agregado - hecho generador, ed. Acali, Montevideo, 1978. VALDÉS COSTA, Ramón. Instituciones de Derecho Tributario, Bs. As., Depalma, 1992.

VAZ FERREIRA, Eduardo. - Tratado de las Sucesiones, T. I, Fac. Der. UdelaR, Montevideo, 1967. VILLANUSTRE NANO, Hugo. "Impuesto a las Trasmisiones Patrimoniales", en Revista Tributaria IUET, T. XX, n. ${ }^{\circ} 113$ (1993), p. 137 y ss.

Fecha de recepción: 5 marzo 2018.

Fecha de aceptación: 14 abril 2018. 
